\title{
The U.S. Geological Survey Land Remote Sensing Program
}

The fundamental goals of the U.S. Geological Survey's Land Remote Sensing (LRS) Program are to provide the Federal Government and the public with a primary source of remotely sensed data and applications and to be a leader in defining the future of land remote sensing, nationally and internationally.

Remotely sensed data provide information that enhance the understanding of ecosystems and the capabilities for predicting ecosystem change. The data promote an understanding of the role of the environment and wildlife in human health issues, the requirements for disaster response, the effects of climate variability, and the availability of energy and mineral resources. Also, as land satellite systems acquire global coverage, the program coordinates a network of international receiving stations and users of the data. It is the responsibility of the program to assure that data from land imaging satellites, airborne photography, radar, and other technologies are available to the national and global science communities.

\section{Program Concepts}

The program encompasses three major components: Remote Sensing Missions and Data Acquisition, Longterm Data Preservation and Access, and Remote Sensing Research and Data Utilization. Each component performs specific tasks to accomplish the program's fundamental mission and primary objectives.

\section{Remote Sensing Missions and Data Acquisitions}

Remote Sensing Missions and Data Acquisitions are a primary source that provides remotely sensed land data from government, commercial, and international assets, including data from
National Technical Means sources. This component of the LRS Program coordinates mission requirements with international cooperators, maintains ground receiving stations, and implements new technologies that support ground data reception and processing in preparation for archiving.

\section{Long-term Data Preservation and Access}

Through the Land Remote Sensing Policy Act of 1992, Congress directed the Secretary of the Interior to establish a public-domain archive of satellite data of the Earth's land surface. The resulting National Satellite Land Remote Sensing Data Archive, managed by the U.S. Geological Survey's Center for Earth Resources Observation and Science (USGS EROS) in Sioux Falls, SD, includes scientifically relevant global land and coastal observation data captured by various land observing satellites and augmented with data from other government, commercial, and international sources.

As the national archive's holdings expand, the collection becomes increasingly valuable for researchers working

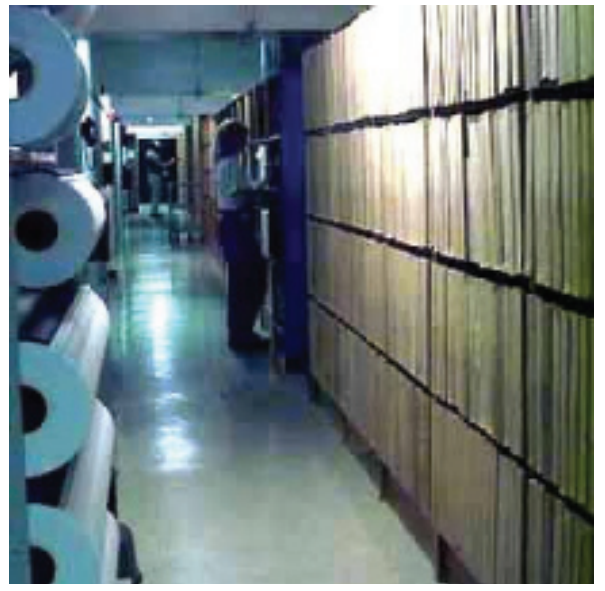

The National Land Remote Sensing Satellite Data Archive at the USGS EROS. to understand natural resources, hazards, and long-term changes. The major focus of this component is to manage and preserve those data so that they remain accessible to a broad range of users over time. This entails employing state-of-theart transcription and archiving technologies, transferring the archives to new media as needed, investigating and implementing advanced media and data storage systems for long-term data preservation, and exploring new ways to make data accessible to customers and cooperators.

\section{Remote Sensing Research and Data Utilization}

This component advances the use of remotely sensed data and remote sensing technology throughout the Department of the Interior and by its cooperators and customers. To accomplish this, the LRS Program conducts and sponsors research in remotely sensed land data collection, access, distribution, and applications from current and future data sources. Scientists and engineers sponsored by the LRS Program are investigating new types of satellite systems and sensors, studying promising new data sources, developing new data acquisition programs and sources, and assessing the potential for new data applications. In addition, the program is seeking new ways to make remotely sensed data products more accessible to the land remote sensing user community, as well as ways to expand and enhance overall use of remotely sensed data and remote sensing technology. The LRS Program is also working to improve product distribution systems and to support new avenues of education and outreach, information access and communication, and remote sensing advocacy.

When Hurricane Katrina hit the south-central coast of the United States in August 2005, Landsat satellite data provided imagery of the affected region. In 


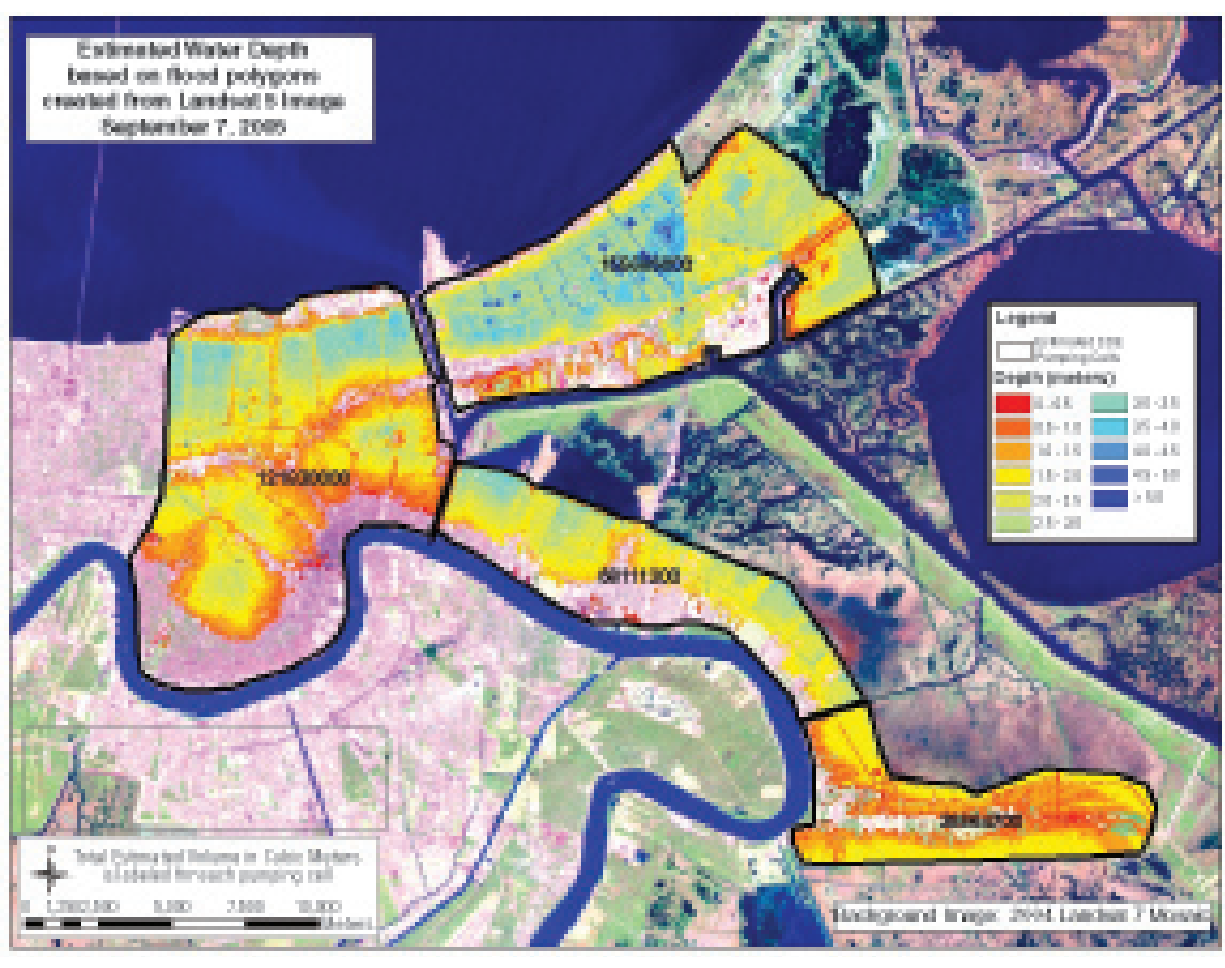

Analysis, based in part on a Landsat image, illustrating the estimated water depth in the immediate New Orleans region after Hurricane Katrina.

addition, historical information and aerial photography of the Louisiana and Mississippi areas were provided to researches and agencies responsible for damage assessment and recovery efforts.

In the past five years, major grassland and forest fires have occurred in the western United States and Alaska. Aerial photography and satellite data were used by LRS Program-sponsored researchers to evaluate fire areas and to help in the planning of preventative measures and recovery activities.

The LRS Program supports a global user community. Entities that benefit from the program include USGS and Department of the Interior programs that use remotely sensed data; other Gov-

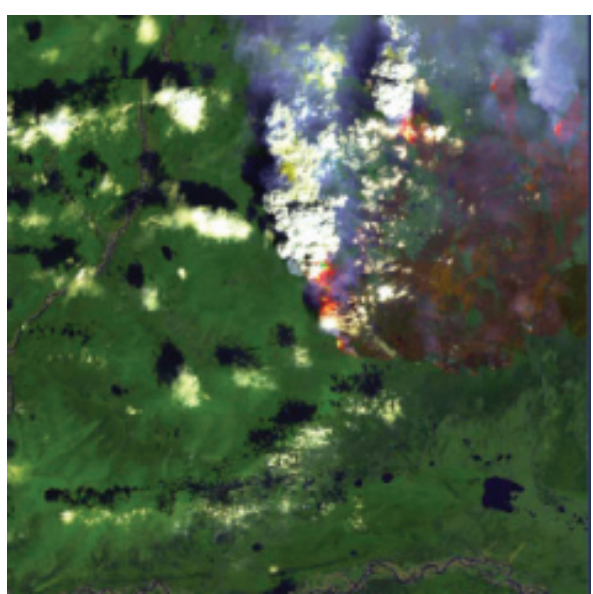

Pingo fire in Alaska, 2005

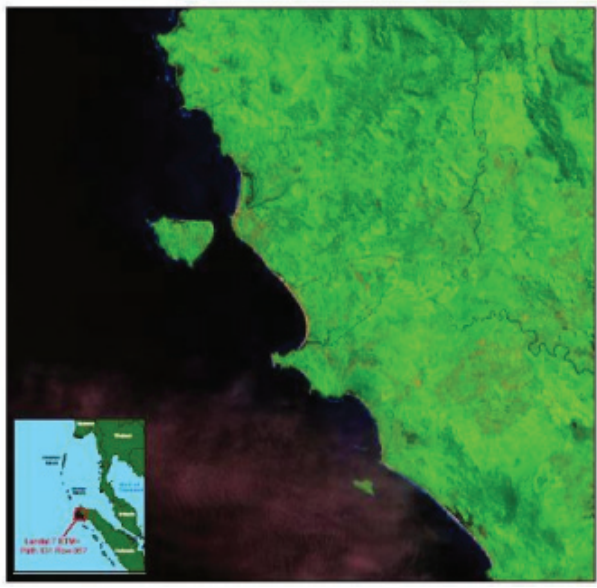

ernment agency programs involved in remotely sensed data collection, analysis and application, land management issues, environmental monitoring, and emergency response; the Landsat international ground station/archive network; commercial value-added processors; and the worldwide user community involved in land remote sensing applications.

For more than 35 years, Landsat satellites have collected data over the planet's land surface to support global research studies. These data constitute the longest continuous record of the Earth's land surface as seen from space. The LRS Program staff are leaders in planning for the Landsat Data Continuity Mission to ensure Landsat data continuity.

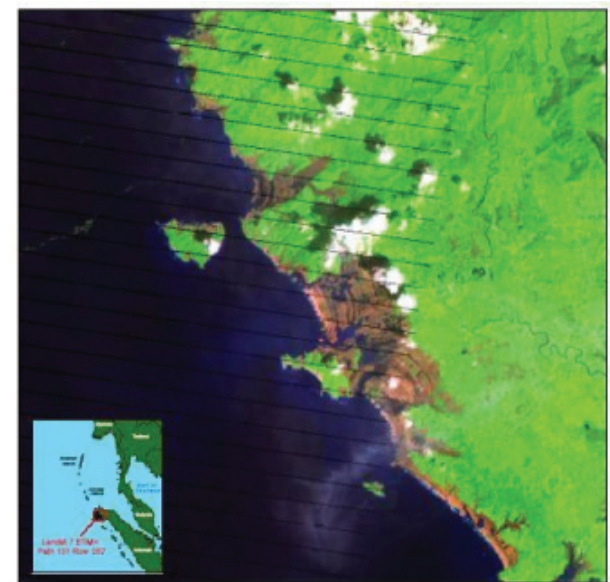

Landsat satellite images of the Sumatra region before and after the December 2004 tsunami.

cal Survey, Geography Discipline, Land Remote Sensing Program at 703-6484567.

For information on other USGS products and services, call 1-888-ASKUSGS, or visit the USGS Publications Warehouse at pubs.usgs.gov.

For additional information, visit the USGS home page at www.usgs.gov. 